\title{
Meditation as Source of Higher States of Consciousness: Mind and Body Healing
}

\section{Made Jessita Kirandra}

Fakultas Psikologi Universitas Airlangga, Surabaya, Indonesia $₫$ made.jessita.kiran2016@psikologi.unair.ac.id

\begin{abstract}
The practice of meditation has been recognized for more than 5,000 years and raised interest in many scientific fields. Yet, meditation is often misconstrued as an activity to empty the entire contents of one's mind. Whereas, in the contradictory fact, studies have shown how meditation helps individuals get acquainted with higher and deeper levels of consciousness through reportedly positive activities on brain. Furthermore, findings also identify meditation as an effective approach to mind-body intervention. This paper is a review on the comprehensive understanding of meditation and how it engages with a phenomenon where the mind and body is seen from a unified perspective, also in the sub-topic will be discussed how artificial intelligence contributes as a convenient tool to facilitate mind-body healing practice through meditation. Findings may help to introduce the general overview of meditation practices that can be adopted to improve mental health in the midst of this digital era.
\end{abstract}

Keywords:Meditation; consciousness; mind-body intervention; mind-body healing.

\section{Introduction}

The era of technology has revolutionized humans' lives in almost every sector, including how perspectives and behaviors are produced. Over the years, it is more than common to find individuals process information very quickly, often resulting in absorbance of a wide assortment of information, whether it is favorable or unfavorable to one's mental health. The nature of technology that easily brings distraction through irrelevant stimuli processed by individuals parallels to the lack of one's consciousnessin performing an activity. Whereas, failure of fully engaging or being conscious of one's thoughts and behaviors can lead to several detriments; from incomplex psychological cases such as the absence of clear thinking and poor decision making, to severe medical impairment such as disorientation and memory loss. 
To attain higher states of consciousness, one must comprehend the term "consciousness" itself. Consciousness is customarily defined as the awareness of one's self or one's environment wherein the aspect of understanding plays an important role (Brooks, 2016). In addition, consciousnessalso refers to the quality or state of wakefulness, involving the totality of sensations, perceptions, ideas, attitudes, and feelings. States of consciousness is concepted as theinteraction of an extensive number of neurological and psychological processes, where reaching an altered state of consciousness involves an intense degree of concentrating one's attention. There are suggestedly five basic ways of producing alterations in consciousness: (1) by decreasing exteroceptive stimulation and/or motor activity; (2) by raising exteroceptive stimulation and/or motor activity and/or emotion; (3) by raising alertness or mental involvement; (4) by lessening alertness or relaxing the critical faculties; and (5) by change or modification in the body chemistry or neurophysiological functioning(Taylor, 2005).

In line with the approaches of producing alterations in consciousness, the practice of meditation has been recognized for more than 5,000 years and continuously becoming an interesting field for research. From its historical view, meditation was introduced to the United States early in the $2^{\text {th }}$ century by Swami Vivekananda and popularized by Paramehansa Yogananda concurrently with Yoga (Puff, 2013).However, many people still miscontrues meditation as an activity to empty the entire content of one's mind. It is also perceived to be done in an identical posture, for instance, sitting on the ground with crossed legs, hand resting on the knees, and eyes slightly narrowed or even completely closed. Whereas, in the contradictory fact, meditation is not just sitting still and emptying the mind. Seen from its meaning, the word "meditation" comes from the Latin "meditari", with the understanding of engaging in contemplation and reflection. It is fathoming all the levels of ourselves and experiencing consciousness within, through specific procedural and attentional training to mindfulness. This activity of contemplation and reflection utilizes different kinds of anchor of one's attention, such as a word, breath, sound, object, or sensation. Perceived from the view of the experts, meditation is a complex process aimed at self-regulating both mind and body.

This paper aims to discuss how meditation helps individuals get acquainted with higher and deeper levels of consciousness through reportedly positive activities on brain. Hypothetically, the psychological and neurophysiological modifications associated with meditation would identify meditation as an effective approach to mind-body intervention. Also, the purpose of this study is to see how artificial intelligence contributes to facilitate mind-body healing practices, including meditation.

\section{Method}

The method used in this paper is content analysis based literature review. Content analysis is defined as:"an approach to quantify qualitative information by systematically sorting and comparing items of information in order to summarize them" (United States Government Accountability Office, 2013). There are two general categories of content analysis: conceptual analysis and relational analysis. Specifically, the method used in this paper is relational analysis, that focuses on finding relationships between concepts. Steps for conducting relational analysis, including: (1) identifying the question; (2) choosing a sample or samples for analysis; (3) determine the type of analysis; (4) reduce the text to categories and code for words or patterns; (5) explore the relationships between concepts (strengths, signs, directions); (6) code the relationships; (7) perform statistical analysis; (8) map out the representations (Colorado State University, 1997-2004).

Disclaimer: Due to the limited time, the method used in this study may not complete full terms of content-analysis method. 


\section{Results and Discussion}

\section{The Effects of Meditation on Consciousness}

From the approach of Buddhist contemplative practice, experience such as emotion, attention, and introspection are processes that continuously needs to be learned, studied, and understood as skills that can be trained. Regarding to this point, the practice of meditation itself is mainly focused on the training of attention and fully experiencing awareness in a complete package of information processed from the five senses.

The effects of meditation on consciousness is more widely discussed from the approach based on brain function. It is acknowledged that the human brain is an organ to which itsfunction is extraordinary, particularly as the central commander of human nervous system. As stated inBrain Facts: A Primer on the Brain and Nervous System Seventh Edition (Society for Neuroscience, 2012), cerebrum, as the largest part of human brain, is divided into two hemispheres, the left and the right. Hemispheres are strongly symmetrical and connected by an array of nerve fibers named the corpus callosum, in which it has a function as the mediator for both hemispheres in interacting.Cerebral cortex, as the outermost layer of cerebrum, is generally a region made up by tightly packed neurons and responsible for higher thought processes. It consists of four lobes: frontal; parietal; temporal; occipital, where each of the lobes has their own respective role in functioning the body. As part of the limbic system located in each of the temporal lobes, it is necessary to acknowledge the role of hippocampus to which function is responsible on the state of orientation. Hippocampal structure, as a consequence of neuroplasticity, is affected from the expertise of each individual. The brain of an expert was found to be functionally and structurally different from a non-expert (Lutz, Dune, \& Davidson, 2007).

An experiment conducted using several methods, involving: electro dermal activity (EDA) measurements, Stroop-word - color test; neurofeedback memory test and meditation(Bob, et al., 2012) showed the important role of interhemispheric interactions in attentional functions. Hemispheres along with other various brain regions enables integration of parallel distributed modalities of processed information resulting to the establish of certain level of efficiency in information processing. After analyzing the data collected using time series analysis, results show that all the participants experiencedthe highest level of information transfer during meditation, facilitated by self-reflective influence of neurofeedback. Through the experiment, it is known that the neurophysiological changes on brain, which is reflected from the increase of brain synchrony, if provided with meditation, are more likely to present a specific consequence of heightened conscious attention.

A longitudinal study on meditation and the neuroscience of consciousness reported experiment results using mid-range meditation practitioners explained how cortical thickness are positively associated with meditation practices. In the experiment, cortical thickness was assessed using magnetic resonance imaging. The study reported that cortical regions associate with attention, interceptive, and sensory processing were found to be thicker in the meditator participants who had an average of 40 minutes of daily insight meditation practice and have been practicing for an average of 9 years (Lutz, Dune, \& Davidson, 2007).

A meta-analysis study (Boccia, Piccardi, \& Guariglia, 2015) also added information about neuroimaging investigations, which in fact disclose the positive effects of meditation to specific brain modifications. Results show that participants who underwent fMRI scans during meditation reported elevated activation in brain areas associated with individual's attention, mind wandering, retrieval of episodic memories, and emotional processing. Meditations broadly share the same central cognitive process, that is regulating attention and advancing a mental outlook of detachment from one's own thoughts. 
Another study of mindfulnes meditation on adults and adolescents with ADHD(Zylowska, et al., 2008) validate precedent phenomenal and remarkable influence to the states of consciousness achieved through meditation practices. The primary practices executed in mindfulness meditation this involves purposeful attention to daily activities-is reported helping working memory trained in patients with ADHD.

\section{Higher States of Consciousness to Mind-Body Healing}

The approach of mind-body connection seen as a unified unit has been strongly stated through many scientific explanations, for example in a form of psychosomatic illnesses. Mind and body dynamically affects one another in a way that results in generating one's behavior.

A study brought by Wim Hof (in Hof, 2015), or commonly known as "The Iceman", shows how consciousness carries effects to the level of body immune. Wim Hof Methods (WHM) consists of three elements: breathing exercises; training of mindset and concentration;and gradual exposure to cold. Anexperiment conducted by the researchers at Radbourd University tried to investigatehow WHM training of mindset and concentration influencedthe activity of his autonomic nervous system and natural immune system, using the injected components of E-coli bacteria into Wim Hof and 112 other participants.In the experiment, Hof showed an impressive reaction, where he produced less than half the number of inflammatory proteins in comparison to the average of the test participants who were also injected with the bacterium. In addition, Hof only suffered a mild headache when the flu symptoms would normally be at their strongest as result of an over-reaction by the immune system.Explaining the findings, reaching to an active state of mind or higher level of consciousness as promoted by the WHM results in decreased levels of the stress hormone "cortisol", that leads to suppression of most inflammatory proteins (cytokines) causing the flu symptoms.

An article of Healing Metabolism: A Naturopathic Medicine Perspective on Achieving Weight Loss and Long Term Balance (Sutherland, 2005) discusses on how obesity is seen as a mind-body issue. One of the relevant deliberationsof this study is that obesity cases are incorporated with the patient's lack of awareness or consciousness in having food intake. According to the study, food as perceived information must intentionally come into one's awareness in the act of eating. Obesity patients oftenperform eating as an unconscious or punitive act irrespective of the nutritional value of the food consumed. Thus, one of the conclusions suggested in this article is giving treatments including providing guidance for patients to becoming aware of one's needs especially in the state of cravings.

Another study, the "Samatha Project"provides incredible methodology applied to investigate relationships among higher states of consciousness, health, and disease. The intervention carried out on the combination of intensive insight and compassion-based intervention. Early results of this study showed that sustained-attention training enhances well-being, leads to more empathic responsiveness to others, thus impacts on both psychological and physiological aspects of health (MacLean, et al., 2010).

\section{Contribution of Artificial Intelligence (AI) to Mind-Body Healing}

With its nature that can trigger a broad impact, including decreased level of consciousness, technology seems to have offered antidote towards humans' mind and body health. Moreover, artificial intelligence (AI) as product of technology has strongly contributed to promote psychological and physiological health.

In meditation practices, technology has offered meditation applications that can be accessed through smart devices as a form of artificial intelligence. After doing an overview, it is found that the rapidly growing meditation applications results in positive feedbacks from its users. The meditation 
application "Muse" users, for instance, stated positive reviews from using the application, such as: making meditation less intimidating; amazingly effective at helping users to focus and relax quickly; worked at drowning out of the thoughts, and allowing to realize the mind when it is drifting into things one's need not think about (Muse, 2018). The "Muse" application itself is a product, comes in a headband that could perform brain-sensing activities together with an application that can be accessed through smartphones. "Muse" claims its use as a brain fitness tool that measures brain signals.

Several tools mentioned are products of artificial intelligence, which function specifically to replace human instructors in the implementation of meditation practices. In addition, Piedmont Health Care(n.d.)made a summary of mindfulness/ meditation applications including how they contribute to mind-body healing, showed in Table 1.1 and Table 1.2.

Table 1.1

\section{MINDFULNESS / MEDITATION APPS}

\begin{tabular}{|c|c|c|c|c|}
\hline APP NAME & LOGO & $\cos T$ & AVAILABILITY & DETAILS \\
\hline The Mindfulness App & & Free & IPhane/Android & $\begin{array}{l}5 \text { day guided meditation practice; meditation } \\
\text { reminders; personalized meditation offers; timers; } \\
\text { Health App integration capability }\end{array}$ \\
\hline Headspace & & $\begin{array}{l}1 \text { 10 exercises free; } \\
\text { optional packages for } \\
\text { fee }\end{array}$ & PPhone/Android & $\begin{array}{l}\text { Take 10-first } 10 \text { exercises to help you better } \\
\text { understand the practice; personalized progress page; } \\
\text { reward system for continued practice; buddy system }\end{array}$ \\
\hline Caim & & Free & IPhone/Android & $\begin{array}{l}\text { Guided medtations from } 3.25 \text { minutes long; Daily } \\
\text { Calm-a } 10 \text { minute program to be practiced daily; } 20 \\
\text { sleep stories; unguided meditations }\end{array}$ \\
\hline MINDBODY & & Free & iPhone/Android & $\begin{array}{l}\text { Ability to book fthess classes; providers fitness } \\
\text { trackers; access to discourts an fitness classes }\end{array}$ \\
\hline buddhify & & $\begin{array}{l}\text { \$4.99-iPhone } \\
\text { \$2.99-Android }\end{array}$ & IPhone/Android & $\begin{array}{l}\text { Access to over } 11 \text { hours of custom meditations; } \\
\text { exercises target specific aspects of } \mathrm{Uf} \text {; exerdises } \\
\text { range from } 5.30 \text { minutes }\end{array}$ \\
\hline Insight Timer & & Free & iPhone/Android & $\begin{array}{l}\text { Features over } 4,500 \text { guided meditations from over } \\
1,000 \text { meditation practitioners; features over } 750 \\
\text { meditation music tracks }\end{array}$ \\
\hline Smiling Mind & & Free & IPhone/Android & $\begin{array}{l}\text { Created for aduits and children > } 7 \text { years old; } \\
\text { sections for educators avalable for use in classroom } \\
\text { settings }\end{array}$ \\
\hline Meditation Timer & & $\$ 0.99$ & ifhone & $\begin{array}{l}\text { Basic meditation exercises; ability to customize } \\
\text { start/stop chimes and background noise }\end{array}$ \\
\hline Sattva & & Free & iPhone & $\begin{array}{l}\text { Daily pre-loaded meditations, chants, timers, mood } \\
\text { trackers; ability to monitor heart rate; reward } \\
\text { system; explains why meditation is beneficial }\end{array}$ \\
\hline Stop, Breathe \& Think & & Free & iPhone/Android & $\begin{array}{l}\text { Over } 55 \text { guided meditations; daily mood tracker; } \\
\text { ability to customize chimes; exercises focus on sleep, } \\
\text { depression and andiety }\end{array}$ \\
\hline Mindfulness Meditation & & $\$ 1.99$ & Android & $\begin{array}{l}\text { Developed by a dinical psychologist; } 2 \text { audio tracks } \\
\text { for meditation; ability to set an intention for exercise }\end{array}$ \\
\hline Simply Being & & $\$ 1.99$ & iPhone/Android & $\begin{array}{l}\text { Customizable guided meditation experience; sessions } \\
\text { range from } 5-30 \text { minutes; ability to choose to } \\
\text { meditate with a quided voice, nature sounds or both }\end{array}$ \\
\hline
\end{tabular}


Table 1.2

\begin{tabular}{|c|c|c|c|c|}
\hline Take A Break! & & Free & iPhone/Android & $\begin{array}{l}\text { Similar to Simply Being, but offers two more guided } \\
\text { meditations }\end{array}$ \\
\hline Omvana & & Free & iPhone/Android & $\begin{array}{l}\text { Connects user to simple meditation music or fully } \\
\text { guided meditation tracks }\end{array}$ \\
\hline Welzen & & Free & iPhone/Android & $\begin{array}{l}\text { Initial } 5 \text { day training course; after training course } \\
\text { ability to access guided meditations for adults and } \\
\text { children; premium meditations available for a fee }\end{array}$ \\
\hline Mindfulness Coach & & Free iPhone & iPhone & $\begin{array}{l}\text { Greated by the Department of Veterans Affairs; } \\
\text { tailored specifically for service members and veterans }\end{array}$ \\
\hline $10 \%$ Happier & & $\$ 7.99$ per month & iPhone/Android & $\begin{array}{l}\text { Meditations led by highly respected mindfulness } \\
\text { teachers; topics include anxiety, political stress, } \\
\text { falling asleep, etc. }\end{array}$ \\
\hline OMG! I Can Meditate & & $\$ 7.42$ per month & iPhone/Android & $\begin{array}{l}\text { Meditations that are broken down into life } \\
\text { events/interests. Examples: chemotherapy, weight } \\
\text { loss }\end{array}$ \\
\hline Relax Melodies & & Free & iPhone/Android & $\begin{array}{l}\text { Simple meditation music to choose from; no guided } \\
\text { meditations }\end{array}$ \\
\hline Remindfulness & & $\$ 2.99$ & iPhone & $\begin{array}{l}\text { Preloaded mindfulness quotes; ability to customize } \\
\text { frequency reminders }\end{array}$ \\
\hline Just Be & & $\$ 0.99$ & Android & $\begin{array}{l}\text { Piatform to create personalized mindfulness quotes; } \\
\text { ability to customize frequency reminders }\end{array}$ \\
\hline In The Moment & & $\$ 1.99$ & iPhone & $\begin{array}{l}\text { Developed by a nutritionist to be used when you feel } \\
\text { hungry; helps you to determine if you are actually } \\
\text { hungry }\end{array}$ \\
\hline Mindful Eating Tracker & & $\$ 2.99$ & iPhone & $\begin{array}{l}\text { Helps to track eating and drinking throughout the } \\
\text { day, as well as your satisfaction with and enjoyment } \\
\text { of those things }\end{array}$ \\
\hline Am I Hungry? & & $\$ 2.99$ & iPhone/Android & $\begin{array}{l}\text { App walks you through mindful eating process when } \\
\text { you are hungry by asking why, when, what, how and } \\
\text { how much }\end{array}$ \\
\hline
\end{tabular}

\section{Conclusions}

As a spiritual and healing practice, meditation is aimed at exploring the therapeutic potential to one's mind and body health. This practice supports the basic concept of mind and body working together dynamically as one unified unit.Findings have shown how meditation practices allow individuals to perceive an event, sensation, or stimulus and reflect it with full awareness without any distortion from associated thoughts and/or attention, including the occurance of restored memories. Meditation techniques such as breath regulation and moving with full awareness provide certain stimulation to the brain and the opportunity for brain to work optimally. This brings impact on the performance of aspects of one's body, both physiologically and psychologically, for example the increased likelihood to attain optimal immune system and reduction of stress. In other words, meditation is approved to treat mind and body health-related issues. In addition, meditation applications have sufficiently described the contribution of $\mathrm{AI}$ as antidote to the broad impact of technology to human behaviors. As a product of AI, meditation applications successfully benefits many users in healing their mind and body.

\section{Acknowledgments}

I would like to thankMr. Rudi Cahyono, M.Psi., Psikolog and Dr. Tjokorda Nirarta Samadhi for their guidance and many helps in the preparation of this paper. 


\section{References}

Brooks, E. M. (2016, April 3). How the Brain Understands: Explanation of Consciousness and Understanding . Imagination, Cognition and Personality, 35(4), 397-412.

Taylor, S. (2005). The Sources of Higher States of Consciousness . International Journal of Transpersonal Studies, 24(1), 48-60.

Puff, R. (2013, July 7). An Overview of Meditation: Its Origins and Traditions. Dipetik January 7, 2017, dari Psychology Today: https://www.psychologytoday.com/blog/meditation-modernlife/201307/overview-meditation-its-origins-and-traditions

Society for Neuroscience. (2012). Brain Facts: A Primer on the Brain and Nervous System Seventh Edition. Washington, United States of America: Society for Neuroscience.

Bob, P., Zimmerman, E. M., Hamilton, E. A., Sheftel, J. G., Bajo, S. D., Raboch, J., . . Konopka, L. M. (2012). Conscious Attention, Meditation, and Bilateral Information Transfer . Clinical EEG and Neuroscience, 44(1), 39-43.

Boccia, M., Piccardi, L., \& Guariglia, P. (2015). The Meditative Mind: A Comprehensive Meta-Analysis of MRI Studies. BioMed Research International, 2015, hal. 1-11.

Zylowska, L., Ackerman, D. L., Yang, M. H., Futrell, J. L., Horton, N. L., Hale, T. S., . . Smalley, S. L. (2008, May). Mindfulness Meditation Training in Adults and Adolescents With ADHD. Journal of Attention Disorders, 11(6), 737-746.

Hof, I. (2015). The Wim Hof Method Explained. Amsterdam: Innerfire.

Sutherland, E. (2005). Healing Metabolism: A Naturopathic Medicine Perspective on Achieving Weight Loss and Long-Term Balance. The Permanente Journal, 9(3), 16-18.

MacLean, K. A., Ferrer, E., Aichele, S. R., Bridwell, D. A., Zanesco, A. P., Jacobs, T. L., . . Saron, C. D. (2010). Intensive Meditation Training Improves Perceptual Discrimination and Sustained Attention. Psychological Science, 21(6), 829-839.

Muse. (2018). What are people saying? Dipetik October 12, 2018, dari Muse: The Brain Sensing Headband: http://www.choosemuse.com/what-are-people-saying/

Piedmont Health Care. (n.d.). Mindfulness/ Meditation Apps. Dipetik October 12, 2018, dari Piedmont Health Care: https://www.piedmont.org/media/file/Dottie-Fuqua-Mindfulness-AppTable.pdf

United States Government Accountability Office. (2013). Content Analysis: Principles and Practices. Washington: United States Government Accountability Office.

Colorado State University. (1997-2004). An Introduction to Content Analysis. Dipetik October 2018, 2018, dari Writing@CSU: Writing Guide: http://www.umsl.edu/ wilmarthp/mrpc-webresources/content-analysis.pdf

Lutz, A., Dune, J. D., \& Davidson, R. J. (2007). Meditation and the Neuroscience of Consciousness. Dalam E. Thompson, P. D. Zelazo, \& M. Moscovitch (Penyunt.), The Cambridge Handbook of Consciousness (hal. 1-101). Cambridge: Cambridge University Press. 